\title{
IMPULSE BUYING TENDENCY: STUDI PADA KONSUMEN MATAHARI DEPARTEMENT STORE KOTA AMBON
}

\author{
Jondry A. Hetharie \\ Sekolah Tinggi Ilmu Ekonomi dan Manajemen (STIEM) Rutu Nusa Ambon \\ e-mail : jondry_UB@rocketmail.com \\ HP. 081331014341
}

\begin{abstract}
Abstrack; This study has the objective to test stimulus which is given from store environment and store social factor toward impulse buying tendency mediated by positive emotion of consumers at Matahari departement store in Ambon City. This study is an explanatory research. Population of this study is consumers who shops in Matahari Department Store in Ambon City. With respondent for 128 people, sampling determination is using purposive sampling method. Data analysis technique in this study is using path analysis. Result of the analysis showed that there are direct effects from physical environment and social aspect of the store toward consumer's positive emotion and toward impulse buying tendency. Result of this study also revealed that there are direct effects of consumer's positive emotion toward impulse buying tendency and indirect effects of store's environment stimulus and store's social factor toward impulse buying tendency mediated by consumer's positive emotion.
\end{abstract}

Keywords: Emosi Positif, Impulse buying tendency

Retailer sangat sadar bahwa bagian volume penjualan yang cukup besar dibangkitkan oleh sifat pembelian impulsif, dimana lebih dari sepertiga di seluruh pembelian pada Department Store dilakukan secara impulsif (Bellenger et al., 1978), sehingga hal ini tentu saja akan berdampak pada naiknya laba perusahaan. Namun bila dilihat dari sisi konsumen seringkali pembelian impulsif secara khusus berhubungan dengan problem keuangan pasca pembelian, produk mengecewakan, perasaan bersalah, dan ketidaksetujuan sosial. Hasil kajian Park (2006), menyatakan bahwa diperkirakan lebih dari 4 Miliar US\$ penjualan tahunan di Amerika Serikat terjadi melalui pembelian impulsif, hasil kajian tersebut relevan dengan pendapat Bellenger et al. (1978) seluruh pembelian pada Department Store dilakukan secara impulsif. 
Realita kondisi lingkungan kota Ambon pasca konflik horisontal dan seiring dengan membaiknya kondisi keamanan serta pemulihan ekonomi (kebijakan recovery ekonomi) yang berhasil dilakukan oleh pemerintah, hal tersebut dapat dibuktikan dengan pertumbuhan ekonomi Kota Ambon yang mencapai 5\% pada tahun 2008 jika dibandingkan dengan pertumbuhan ekonomi sebesar 0\% di tahun 1999. Kondisis tersebut mendorong perkembangan aktivitas bisnis pada umumnya, termasuk mempengaruhi perkembangan sektor perdagangan di Kota Ambon. Berdasarkan hasil survei ISSS Index tahun 2007 mengenai persaingan departement store menunjukan bahwa Matahari departement store paling memuaskan konsumen. Study ini pada dasarnya merupakan penelitian replikasi ekstensi yang didasarkan pada penelitian terdahulu yang dilakukan oleh Mattila dan Wirtz (2006) dengan judul "The Role Of Store Environmental Stimulations And Social Factors On Impulse Purchasing ".Penelitian Mattila dan Wirtz (2006) bertujuan untuk mengetahui peranan dari stimulasi yang disebabkan oleh lingkungan toko dalam mempengaruhi pembelian impulsif, selain itu mereka mencoba menyelidiki dampak dari 2 faktor sosial yaitu persepsi keramaian dan keterlibatan karyawan.

Penelitian Mattila dan Wirtz (2006) memiliki keterbatasan yang dapat pula dijadikan research gap dalam penelitian ini. Penelitian Mattila dan Wirtz (2006) tidak menunjukan efek atau pengaruh respons emosi positif konsumen terhadap pembelian impulsif, sedangkan penelitian yang dilakukan oleh Park, E. J, et al (2005) dengan judul " A Structural Model Of Fashion-Oriented Impulse Buying Behavior" menemukan bahwa emosi positif memiliki pengaruh positif terhadap pembelian secara impulsif, konsumen yang memiliki perasaan positif, seperti merasa senang, gembira dan puas secara impulsif akan melakukan pembelian lebih banyak dalam perjalanan belanja mereka. Hal ini diperkuat dengan penelitian yang dilakukan oleh Eckman dan Yan (2009) dengan judul "Impulse Buying Behavior Of apparel: Application Of The S-O-R Model and The Moderating Effect Of Hedonic Motivation " menunjukan bahwa stimulus yang disebabkan oleh lingkungan toko dan factor sosial berpengaruh positif terhadap respons emosi positif dari konsumen. Temuan chang dan park juga diperkuat oleh temuan Sherman,Marthur,dan Smith.,1997 dengan judul "Store Environment and Consumer Purchase Behavior:Mediating Role of Consumer Emotions". Dengan menggunakan 
kerangka stimulus-organisme-respons, menunjukan hasil bahwa emosi konsumen bisa menjadi faktor mediasi dalam proses pembelian.

Adanya perbedaan hasil pnelitian atau mengenai pengaruh stimulus dari lingkungan fisik dan faktor sosial terhadap pembelian impulsif menjadikan fenomena ini menarik untuk diteliti lebih mendalam dengan menguji kembali keberadaan variabel emosi positif dan pengaruhnya terhadap pembelian impulsif.

Berdasarkan uraian yang telah dipaparkan diatas baik secara empiris ataupun teoritis, maka muncul pertanyaan baru dalam penelitian ini yaitu : Bagaimana pengaruh variabel stimulus dari lingkungan fisik dan faktor sosial baik secara langsung maupun tidak langsung terhadap pembelian impulsif dan pengaruh respons emosi positif konsumen sebagai variabel intervening terhadap pembelian impulsif pada Matahari Dapertement Store Ambon Plaza Kota Ambon?

\section{Ritel Modern}

Arti Modern disini adalah penataan barang menurut keperluan yang sama dikelompokkan dibagian yang sama yang dapat dilihat dan diambil langsung oleh pembeli, penggunaan AC, pramuniaga professional (Ma'aruf, 2005). Kemudian Ritel modern pertama kali hadir di Indonesia saat Toserba Sarinah didirikan pada 1962. Pada era 1970 s/d 1980-an, format bisnis ini terus berkembang. Awal dekade 1990-an merupakan tonggak sejarah masuknya ritel asing di Indonesia. Ini ditandai dengan beroperasinya ritel terbesar Jepang 'Sogo' di Indonesia. Ritel modern kemudian berkembang begitu pesat saat pemerintah, berdasarkan Kepres no. 99 th 1998, mengeluarkan bisnis ritel dari negatif list bagi Penanaman Modal Asing. Sebelum Kepres 99 th 1998 diterbitkan, jumlah peritel asing di Indonesia sangat dibatasi (Media data, Peta Persaingan Bisnis Ritel di Indonesia, pg. 63, 2009).

Strategi pemasaran ritel juga mengacu kepada variabel, dimana pedagang eceran dapat mengkombinasikan menjadi jalan alternatif sebagai suatu strategi pemasaran untuk dapat menarik konsumen. Variabel tersebut umumnya meliputi faktor seperti: variasi barang dagangan dan jasa yang ditawarkan, harga, iklan, promosi, dan tata ruang, desain store, lokasi store dan merchanding. 
Untuk menjaga kelangsungan hidup serta kemajuan dan keunggulan dalam bisnis eceran yang semakin kompetitif, maka pengelola bisnis tersebut harus berupaya menerapkan strategi berupa program bauran penjualan eceran yang diharapkan memunculkan minat konsumen.

\section{Faktor Situasional}

Menurut Mowen dan Minor (2001) dalam Rohman (2009) faktor situasional merupakan lingkungan sementara yang membentuk konteks dalam suatu kegiatan konsumen, yang terjadi pada waktu dan tempat tertentu. Dari definisi tersebut dapat diartikan bahwa situasional: pertama, melibatkan tempat dan waktu. Kedua, menjelaskan mengapa perilaku terjadi. Ketiga, mempengaruhi perilaku konsumen. Lebih lanjut Mowen dan Minor (2001) dalam Rohman (2009) menyatakan, faktor situasional merupakan peristiwa yang relatif pendek dan harus dibedakan dari faktor lingkungan jangka panjang, seperti pengaruh kebudayaan, serta faktor perorangan yang memiliki kualitas lebih tahan lama, seperti kepribadian individual.

\section{Pembelian Impulsif}

Pembelian impulsif menurut Beatty dan Ferrell (1998) adalah suatu pembelian yang segera dan tiba-tiba tanpa adanya niat sebelum belanja, untuk membeli kategori produk yang spesifik dan untuk memenuhi kebutuhan tertentu. Perilaku terjadi setelah mengalami suatu dorongan untuk membeli yang sifatnya spontan tanpa banyak refleksi. Menurut Hausman (2000), pembelian impulsif terjadi ketika konsumen mengalami suatu kejadian yang mendadak, sering kali muncul dorongan yang sangat kuat untuk membeli sesuatu dengan segera.

\section{Emosi Positif}

Pada dasarnya pendekatan psikologi mengajukan pandangannya mengenai perilaku manusia bahwa perilaku manusia dipengaruhi oleh lingkungannya. Hal tersebut diantaranya dapat dilihat dari formulasi yangdilakukan Lewin (dalam Negara, 2002) dari hasil formulasi tersebut ditemukan bahwa perilaku merupakan fungsi dari kepribadian dan lingkungan. 
Dari hubungan ketiganya kemudian diamati lebih mendalam oleh Mehrabian dan Russel dengan memasukkan variable mediasi yakni faktor emosi individu. Hal ini sejalan dengan paradigma S-O-R yang mendasarinya. Taman dalam Tirmizi,et al. (2009) menemukan hubungan positif emosi positif, keterlibatan mode fashion dengan pembelian impulsif.

Menurut Park, et al. (2006) emosi adalah sebuah efek dari mood yang merupakan faktor penting konsemuen dalam kputusan pembelian. Faktor perasaan/emosi merupakan konstruk yang bersifat temporer karena berkaitan dengan situasi atau objek tertentu. Perasaan seperti jatuh cinta, sempurna, gembira, ingin memiliki, bergairah, terpesona, dan antusias,dari berbagai studi, disinyalir memiliki korelasi positif yang signifikan dengan kecenderungan melakukan pembelian impulsif (Premananto, 2007).

\section{Kerangka Konseptual}

Agar penelitian ini dapat terarah secara sistematis dalam suatu alur metode penelitian yang yang baik, sesuai dengan rumusan masalah dan tujuan yang akan dicapai. Kerangka konsep penelitian secara komprehensif perlu dibangun dengan mendasarkan kepada fakta masalah yang ada.

\section{Gambar 1.}

\section{Kerangka Proses Berpikir}

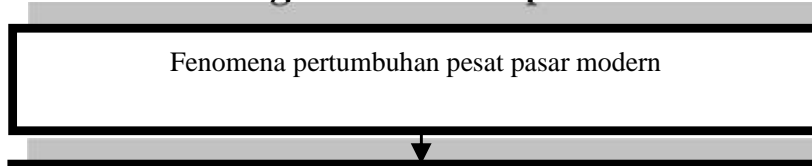

Adanya faktor-faktor yang mendorong konsumen dalam melakukan pembelian impulsif, yaitu Stimulus Lingkungan Toko, Sosial Toko, Emosi Positif

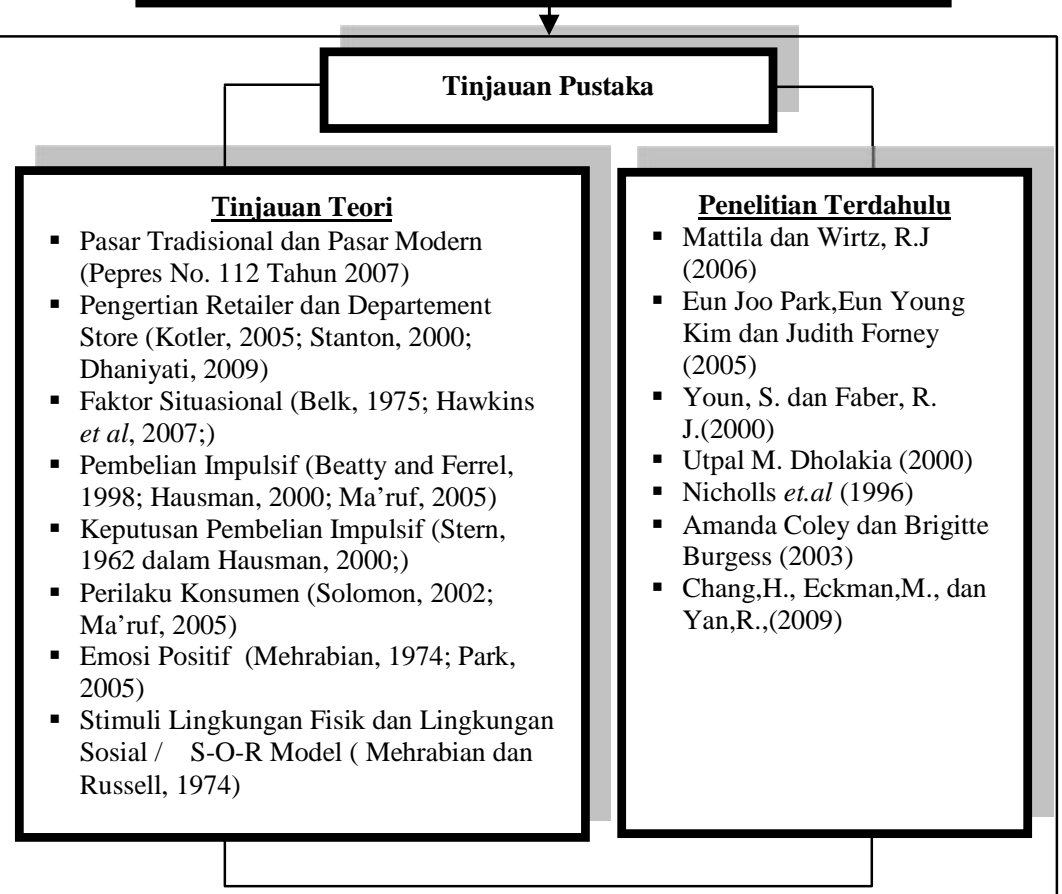


Gambar 2.

Kerangka Konseptual dan Hubungan Antar Variabel

STIMULUS

( $S$ )

Stimulus lingkungan toko (X1)

Musik

Warna

Aroma

Ketersediaan Produk

Sosial Toko (X2)

Persepsi tingkat

keramaian

Peran Karyawan
ORGANISM

( O )

RESPONS

( R )

$\mathrm{H}$

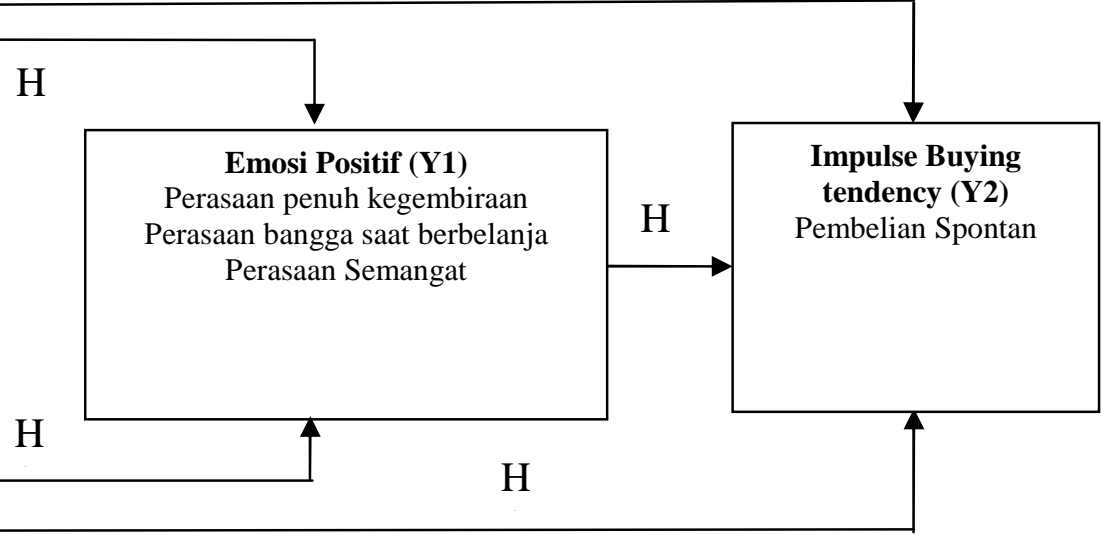

Sumber: Mattila dan Wirtz(2006), Chang,H.,Eckmand, M., dan Yan, R.,(2009)

Hipotesis:

H1 : Stimulus lingkungan toko berpengaruh lansung terhadap emosi positif konsumen

H2 : Stimulus lingkungan toko berpengaruh secara langsung terhadap impulse buying tendency 
H3 : Sosial toko berpengaruh langsung terhadap emosi positif konsumen

H4 : Sosial toko berpengaruh langsung terhadap impulse buying tendency

H5 : Emosi positif konsumen berpengaruh langsung terhadap impulse buying tendency

H6 : Stimulus lingkungan toko berpengaruh tidak langsung terhadap impulse buying tendency melalui emosi positif konsumen

H7 : Sosial toko berpengaruh tidak langsung terhadap impulse buying tendency melalui emosi positif konsumen

\section{METODE}

Penelitian ini termasuk dalam penelitian eksplanatory. Penelitian eksplanatory adalah suatu betuk penelitian yang menjelaskan hubungan antara variabel dan pengujian hipotesis yang telah dirumuskan sebelumnya (Singarimbun, 1995 dalam Musa, 2010). Sedangkan pendekatan yang digunakan pada penelitian ini adalah pendekatan kuantitatif, yaitu penelitian dengan pendekatan angka-angka baik dalam pengumpulana data, analisa data sampai interpretasi data didasarkan pada hasil analisa data yang berupa angka. Sedangkan unit analisis yang dipergunakan dalam penelitian ini adalah individu konsumen yang melakukan belanja pada Matahari departement store di Kota Ambon.

Penelitian ini dilaksanakan di Matahari departement store yang terdapat di kota Ambon. Kota Ambon dipilih sebagai lokasi penelitian dengan pertimbangan bahwa kota ini merupakan Ibukota provinsi dan merupakan pusat bisnis di Kota Ambon. Alasan penelitian dilakukan di Matahari departement store karena merupakan satu-satunya pusat perbelanjaan terbesar di Kota Ambon. Populasi dalam penelitian ini adalah keseluruhan pelanggan yang melakukan pembelian impulsif pada produk pakaian di Matahari departement store di Kota Ambon. Jumlah sampel yang sesuai untuk suatu penelitian menurut Davis dan Cosenza (1993) dalam Kuncoro, 2003 dan Rohman, 2009 dipengaruhi oleh alat analisis yang dipergunakan. Alat analisis dalam penelitian ini menggunakan Path Analysis. Penelitian yang menggunakan Path Analysis jumlah sampel yang sesui 
adalah 100 (Ding, Velicer, dan Harlow (1995) dalam Supranto, 2004 dan Rohman, 2009). Dan menurut Sarwono (2007:3) ukuran sampel yang memadai dan untuk memperoleh hasil yang maksimal dalam analisis jalur, sebaiknya digunakan sampel diatas 100. Berdasarkan ketentuan tersebut maka jumlah sampel yang digunakan dalam penelitian ini adalah 128 responden.

\section{Analisis Jalur (Path Analysis)}

Metode untuk menganalisa data dalam penelitian ini menggunakan analisa jalur. Menurut Ridwan dan Kuncoro (2007) menyatakan bahwa analisis jalur digunakan untuk menganalisis pola hubungan antar variabel dengan tujuan untuk mengetahui pengaruh langsung maupun tidak langsung seperangkat variabel eksogen terhadap variabel endogen.

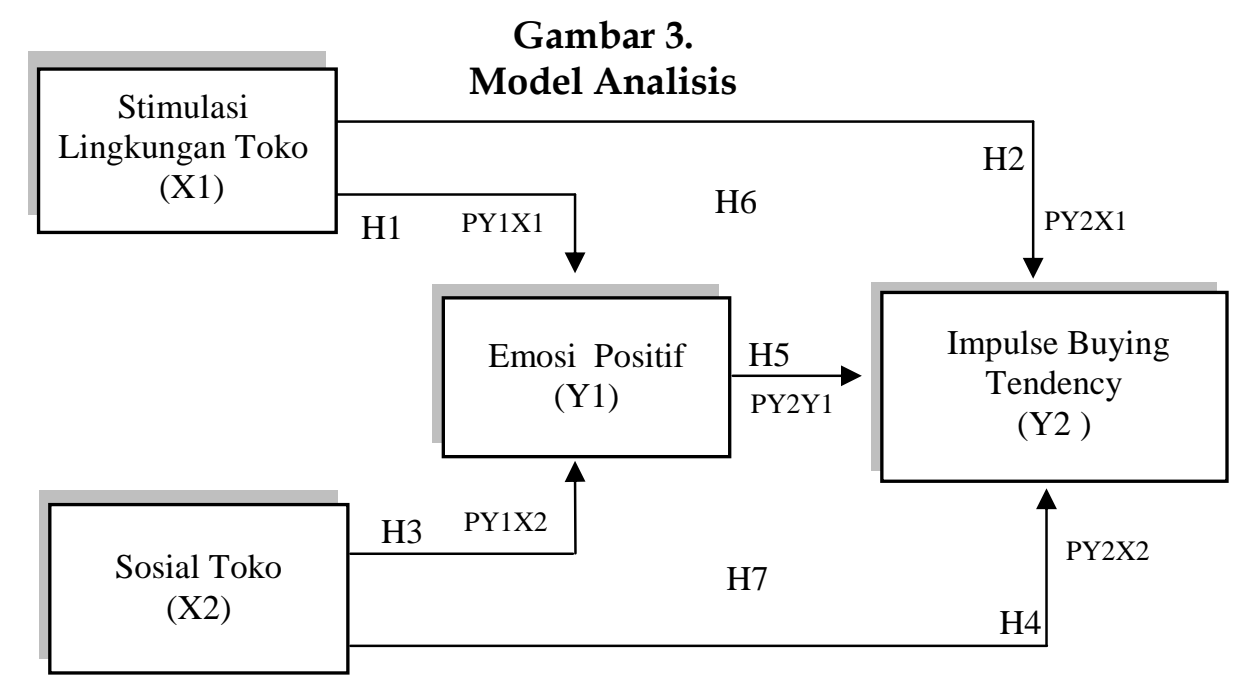

Keterangan :

Persamaan untuk model hipotesis jalur adalah :

$\begin{array}{ll}\mathrm{Y} 1 & =\mathrm{a}+\mathrm{b}_{1} \mathrm{X}_{1}+\mathrm{b}_{2} \mathrm{X}_{2}+\varepsilon \\ \mathrm{Y} 2 & =\mathrm{a}+\mathrm{b}_{1} \mathrm{X}_{1}+\mathrm{b}_{2} \mathrm{X}_{2}+\mathrm{b}_{3} \mathrm{Y}_{1}+\varepsilon\end{array}$

Dimana :

Y1 = Emosi positif 


$$
\begin{array}{ll}
\mathrm{Y} 2 & =\text { Impulse Buying Tendency } \\
\mathrm{X} 1 & =\text { Stimulus lingkungan toko } \\
\mathrm{X} 2 & =\text { Sosial toko } \\
\varepsilon & =\text { Error }
\end{array}
$$

\section{HASIL}

\begin{tabular}{|c|c|c|c|c|c|}
\hline Variabel & Indikator & Item & $\mathbf{R}$ & Sig & Ket \\
\hline \multirow{5}{*}{$\begin{array}{c}\text { Stimulus } \\
\text { Lingkungan } \\
\text { Toko (X1) }\end{array}$} & \multirow{2}{*}{ Musik } & 1 & 0,897 & 0,000 & Valid \\
\hline & & 2 & 0,787 & 0,000 & Valid \\
\hline & Warna & 3 & 0,714 & 0,000 & Valid \\
\hline & Aroma & 4 & 0,787 & 0,000 & Valid \\
\hline & $\begin{array}{l}\text { Ketersediaan } \\
\text { Produk }\end{array}$ & 5 & 0,842 & 0,000 & Valid \\
\hline \multirow{4}{*}{$\begin{array}{c}\text { Variabel } \\
\text { Sosial Toko } \\
\text { (X2) }\end{array}$} & $\begin{array}{c}\text { Persepsi Tingkat } \\
\text { Keramaian }\end{array}$ & 1 & 0,906 & 0,000 & Valid \\
\hline & \multirow{3}{*}{ Peran Karyawan } & 2 & 0,925 & 0,000 & Valid \\
\hline & & 3 & 0,887 & 0,000 & Valid \\
\hline & & 4 & 0,916 & 0,000 & Valid \\
\hline \multirow{3}{*}{$\begin{array}{c}\text { Variabel } \\
\text { Emosi } \\
\text { Positif (Y1) }\end{array}$} & $\begin{array}{c}\text { Perasaan } \\
\text { Senang/Gembira }\end{array}$ & 1 & 0,833 & 0,000 & Valid \\
\hline & Perasaan Bangga & 2 & 0,911 & 0,000 & Valid \\
\hline & $\begin{array}{l}\text { Perasaan } \\
\text { Semangat }\end{array}$ & 3 & 0,928 & 0,000 & Valid \\
\hline \multirow{3}{*}{$\begin{array}{l}\text { Variabel } \\
\text { Impulse } \\
\text { buying } \\
\text { tendency } \\
\text { (Y2) }\end{array}$} & & 1 & 0,938 & 0,000 & Valid \\
\hline & & 2 & 0,778 & 0,000 & Valid \\
\hline & & 3 & 0,929 & 0,000 & Valid \\
\hline
\end{tabular}

\section{Hasil Uji Validitas}

Tabel 1

Hasil Uji Validitas Instrumen Penelitian

Sumber: Data Primer (diolah), 2011 
Berdasarkan tabel tersebut dapat diketahui bahwa semua item pertanyaan memiliki nilai probabilitas kurang dari 0,05 sehingga dapat dikatakan semua item pertanyaan telah valid untuk pengujian selanjutnya

\section{Uji Reliabilitas}

Tabel 2

Hasil Pengujian Reliabilitas Instrumen Penelitian

\begin{tabular}{|c|c|c|}
\hline Variabel & Koefisien Alpha & Keterangan \\
\hline $\begin{array}{c}\text { Stimulus Lingkungan Toko } \\
(\mathrm{X} 1)\end{array}$ & 0,864 & Reliabel \\
\hline $\begin{array}{c}\text { Variabel Sosial Toko (X2) } \\
\text { Variabel Emosi Positif } \\
\text { (Y1) }\end{array}$ & 0,929 & Reliabel \\
\hline $\begin{array}{c}\text { Variabel Kecenderungan } \\
\text { Pembelian Tidak } \\
\text { Terencana }\end{array}$ & 0,867 & Reliabel \\
\hline
\end{tabular}

Sumber: Data Primer (diolah), 2011

Berdasarkan tabel di atas dapat diketahui bahwa semua variabel memiliki nilai koefisien Alpha Cronbach lebih besar dari 0,6 sehingga dapat dikatakan instrumen pertanyaan yang digunakan dalam penelitian ini sudah reliabel atau dapat dihandalkan dan dapat dilakukan pengujian selanjutnya.

\section{Interpretasi Path}

Dari kedua persamaan tersebut, diperoleh hasil analisis jalur (path) secara keseluruhan adalah:

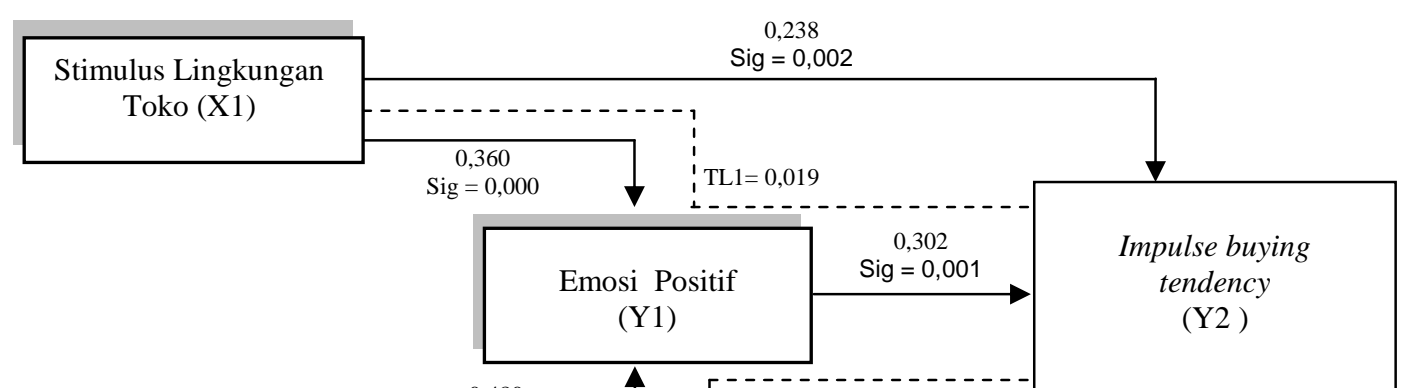


Tabel 3

Pengaruh Langsung dan Tidak Langsung

\begin{tabular}{|c|c|c|c|c|}
\hline $\begin{array}{c}\text { Variabel } \\
\text { Eksogen }\end{array}$ & $\begin{array}{c}\text { Variabel } \\
\text { Endogen }\end{array}$ & $\begin{array}{c}\text { Pengaruh } \\
\text { Langsung }\end{array}$ & $\begin{array}{c}\text { Pengaruh Tidak } \\
\text { Langsung }\end{array}$ & $\begin{array}{c}\text { Pengaruh } \\
\text { Total }\end{array}$ \\
\hline $\begin{array}{c}\text { Stimulus } \\
\text { Lingkungan } \\
\text { Fisik (X1) }\end{array}$ & $\begin{array}{c}\text { Emosi Positif } \\
(\mathrm{Y} 1)\end{array}$ & 0,360 & - & 0,360 \\
\hline $\begin{array}{c}\text { Stimulus } \\
\text { Lingkungan } \\
\text { Fisik (X1) }\end{array}$ & $\begin{array}{c}\text { Kecenderungan } \\
\text { pembelian } \\
\text { Impulsif (Y2) }\end{array}$ & 0,238 & $\begin{array}{c}\text { Dimediasi oleh } \\
\text { Emosi Positif, } \\
0,360 \times 0,302 \\
=0,109\end{array}$ & 0,347 \\
\hline $\begin{array}{c}\text { Sosial Toko } \\
(\mathrm{X} 2)\end{array}$ & $\begin{array}{c}\text { Emosi positif } \\
(\mathrm{Y} 1)\end{array}$ & 0,480 & - & 0,480 \\
\hline $\begin{array}{c}\text { Sosial toko } \\
(\mathrm{X} 2)\end{array}$ & $\begin{array}{c}\text { Impulse buying } \\
\text { tendency (Y2) }\end{array}$ & 0,354 & $\begin{array}{c}\text { Dimediasi oleh } \\
\text { Emosi Positif, }\end{array}$ & 0,499 \\
\hline $\begin{array}{c}\text { Emosi Positif } \\
(\mathrm{Y} 1)\end{array}$ & $\begin{array}{c}\text { Impulse buying } \\
\text { tendency (Y2) }\end{array}$ & 0,302 & & 0,499 \\
\hline
\end{tabular}

Sumber : Data Primer Diolah, 2011

\section{PEMBAHASAN}

Hasil penelitian ini menunjukan bahwa terdapat pengaruh langsung aspek lingkungan fisik dalam hal ini stimulus yang diberikan dari pihak matahari departement store kota ambon terhadap emosi konsumen dan impulse buying tendency dalam hal ini adalah emosi positif yang dirasakan konsumen pada saat berkunjung ke matahri departement store. Perasaan senang yang dirasakan konsumen mengarah kepada peningkatan pembelian impulsif. Stimulus berupa musik, warna, aroma, dan ketersediaan produk yang diberikan oleh pihak matahari idepartement store kota ambon berdampak pada peningkatan minat konsumsi dan impulse buying tendency. Hasil penelitian ini 
juga sejalan dengan penelitian Mattila and Wirtz (2001) yang menyatakan bahwa ketika aroma lingkungan toko dan musik saling kongruen satu sama lain maka penilaian konsumen terhadap lingkungan menjadi lebih positif dan menunjukan level pendekatan yang lebih tinggi dan perilaku pembelian tdak terencana, dan mengalami kepuasan yang semakin tinggi jika dibandingkan dengan saat isyarat lingkungan ini saling tidak berkesesuaian satu sama lain (musik,warna.dan aroma).

Hasil kajian membuktikan bahwa terdapat pengaruh langsung faktor sosial toko (diindikasikan dalam konteks peran karyawan dan persepsi keramaian yang dirasakan konsumen) terhadap emosi positif konsumen dimana keramahan dan bantuan yang diberikan karyawan kepada pelanggan membuat mereka merasa tersanjung dan dihargai sehingga mereka merasakan kenyamanan dalam berbelanja. Hasil penelitian ini juga sejalan dengan hasil kajian Matilla and Wirts (2006), yang menyatakan bahwa terdapat hubungan yang signifikan antara stimulus yang lebih optimal dari lingkungan toko terhadap perilaku pembelian impulsif, serta faktor lingkungan sosial (tingkat kepadatan dan keramahan karyawan) berpengaruh signifikan terhadap pembelian impulsif. Emosi konsumen pada waktu berbelanja mendukung keinginannya untuk melakukan interaksi dengan orang lain sehingga membuat pengalaman berbelanja mereka menjadi menyenangkan (cobb dan Hoyer, 1986) dalam (Rohman, 2009). Hasil studi ini menunjukan bahwa emosi positif dalam hal ini suasana hati yang dirasakan (perasaan senang dan bangga) pada waktu berbelanja dapat mempengaruhi rasa senang konsumen yang positif pada waktu berbelanja di matahari departement store kota ambon. Emosi positif yang dirasakan oleh konsumen pada waktu berbelanja mempengaruhi keputusan pembelian. Hal ini sejalan dengan kajian (Premananto, 2007). Emosi positif yang dirasakan konsumen akan mendorong konsumen untuk mengakuisisi suatu produk dengan segera tanpa adanya perencanaan yang mendahuluinya dan sebaliknya emosi yang negatif dapat mendorong konsumen untuk tidak melakukan pembelian impulsif. 
Hasil penelitian ini juga membuktikan adanya pengaruh tidak langsung stimulus lingkungan toko terhadap impulse buying tendency melalui emosi positif konsumen. hasil penelitian membuktikan bahwa emosi positif memediasi pengaruh stimulus lingkungan toko terhadap impulse buying tendency. Hal ini sesuai dengan kajian Park, et al (2005) dalam penelitiannya menemukan bukti bahwa emosi positif menghasilkan sebuah pengaruh positif terhadap perilaku pembelian secara impulsif. Hasil penelitian menunjukan bahwa konsumen yang memiliki perasaan senang dan merasa puas, secara impulsif akan membeli lebih banyak produk selama perjalanan belanja mereka. Hasil ini mendukung kecenderungan kondisi emosional positif dalam mengurangi kerumitan pengambilan keputusan,mengarah pada pembelian impulsif (Babin, 2001; Youn dan Faber, 2000).

Pelaku ritel harus memberikan perhatian pada kondisi emosional positif konsumen dan pengalaman hedonis dalam toko (in-store) mereka karena hal ini dapat memicu perilaku pembelian impulsif, juga pelaku ritel terus menerus mendorong pembelian impulsif yang dilakukan oleh konsumen dan juga mendorong terjadinya emosi positif melalui desain toko, display produk, desain kemasan dan penjualan (Park et al, 2005). Emosi yang mencakup afeksi dan mood adalah sebuah faktor penting dalam pengambilan keputusan konsumen. Biasanya, emosi diklasifikasikan ke dalam dua dimensi yang ortogonal (misal, positif dan negatif) (Watson dan Tellegen, 1985). Sejumlah studi kualitatif melaporkan bahwa konsumen merasa bersemangat atau berenergi setelah melakukan sebuah pengalaman berbelanja (shopping experience) (Bayley dan Nancarrow, 1998; Dittmar et al., 1996; Rook, 1987 dalam Park, 2005).

Emosi sangat mempengaruhi aksi/tindakan termasuk perilaku pembelian impulsif (Beatty dan Ferrell, 1998; Hausman, 2000; Rook dan Gardner, 1993; Youn dan Faber, 2000 dalam Park, 2005). Konsumen dalam kondisi emosional yang lebih positif cenderung untuk mengurangi kerumitan pengambilan keputusan dan memiliki waktu pengambilan keputusan yang lebih pendek (Isen, 1984). Terlebih lagi, jika dibandingkan dengan emosi negatif, konsumen yang memiliki emosi positif menunjukkan perilaku pembelian tidak 
terencana lebih besar karena merasa tidak terikat, memiliki sebuah keinginan untuk memberikan penghargaan pada diri mereka sendiri dan memiliki level energi yang lebih tinggi (Rook dan Gardner, 1993).

Sementara berbelanja, emosi di dalam toko dapat mempengaruhi niat membeli dan menghabiskan uang serta mempengaruhi persepsi kualitas, kepuasan dan value (Babin dan Babin, 2001). Beatty dan Ferrell (1998) menemukan emosi positif konsumen diasosiasikan dengan dorongan untuk membeli. Hal ini mendukung penemuan awal bahwa para pembeli dengan impuls (impulse buyer) lebih emosional daripada para pembeli non-impuls (Weinberg dan Gottwald, 1982). Karena perilaku pembelian tidak terencana menunjukkan perasaan positif yang lebih besar (misal, rasa senang, excitement, joy), mereka seringkali menghabiskan lebih banyak uang ketika berbelanja (Donovan dan Rossiter, 1982). Terlebih lagi, pembelian pakaian jadi yang tidak direncanakan memuaskan kebutuhan emosional yang berasal dari interaksi sosial yang muncul dalam pengalaman berbelanja (Cha, 2001 dalam Park, 2005). Oleh karenanya, emosi konsumen bisa menjadi sebuah penentu penting dalam memprediksikan pembelian impulsif dalam sebuah toko ritel.

\section{KESIMPULAN DAN SARAN}

\section{Kesimpulan}

Hasil studi ini secara keseluruhan dapat disimpulkan bahwa impulse buying tendency dipengaruhi oleh stimulus lingkungan toko dan faktor sosial toko baik secara langsung maupun secara tidak langsung dimediasi oleh emosi positif. Hasil studi membuktikan bahwa variabel sosial toko memiliki pengaruh yang lebih dominan baik secara langsung maupun secara tidak langsung terhadap impulse buying tendency di matahari departement store Kota Ambon.

Kesimpulan umum tersebut dapat dijabarkan secara lebih rinci sebagai berikut; Pertama, peningkatan stimulus lingkungan toko yang teraktualisasi dalam hal penataan lingkungan toko dan stimulus yang diberikan berupa musik, aroma, warna, dan ketersediaan produk di Matahari departement store Kota Ambon dapat mempengaruhi emosi positif konsumen. Kedua, peningkatan 
stimulus lingkungan toko yang teraktualisasi dalam Matahari departement store Kota Ambon membuat konsumen cenderung untuk melakukan pembelian impulsif.

Ketiga, faktor sosial toko dalam hal ini tingkat keramaian dan peran karyawan di dalam Matahari departement store Kota Ambon mempengaruhi emosi positif konsumen sehingga dapat mempengaruhi keputusan pembelian. Ke-empat, Factor sosial toko dalam hal ini tingkat keramaian dan peran karyawan di dalam Matahari departement store Kota Ambon membuat konsumen cenderung melakukan pembelian impulsif. Kelima, emosi yang dirasakan konsumen yang terktualisasi dengan sikap positif pelanggan dalam hal, sikap yang merasa senang dan bangga sewaktu berbelanja di Matahari departement store Kota Ambon.

Persepsi ini dalam konteks pendapat pelanggan bahwa berbelanja di Matahari departement store Kota Ambon merupakan aktivitas yang menyenangkan dan merupakan kegiatan atau aktivitas favorit bagi individu sehingga dapat mempengaruhi keputusan pembelian impulsif. Keenam, peningkatan stimulus lingkungan toko yang teraktualisasi dalam hal penataan lingkungan toko dan stimulus yang diberikan berupa musik, aroma, warna, dan ketersediaan produk di Matahari departement store Kota Ambon dapat merangsang emosi positif konsumen sehingga dapat memicu terjadinya pembelian impulsif. Ketujuh, faktor sosial toko dalam hal ini tingkat keramaian dan peran karyawan di dalam Matahari departement store Kota Ambon mempengaruhi emosi positif konsumen sehingga cenderung terjadinya pembelian impulsif.

\section{Saran}

Berdasarkan hasil penelitian yang telah diuraikan pada bab terdahulu, maka ada beberapa saran yang perlu ditindak lanjuti. Adapun saran-saran berikut ini: Pertama, pihak Matahari departement store Kota Ambon diharapkan dapat menata lingkungan toko yang teratur dengan interior yang lebih nyaman dan menarik lagi guna membentuk sikap positif pelanggan terhadap lingkungan 
toko. Kedua, pihak Matahari departement store Kota Ambon perlu untuk lebih intens dalam menginformasikan produk-produk yang dijual khususnya barang baru, guna membentuk pemahaman konsumen tentang persediaan barang di Matahari departement store Kota Ambon, pengetahuan yang dimiliki oleh pelanggan diasumsikan akan timbul kepercayaan-kepercayaan yang dapat dikomunikasikan kepada pelanggan lain.

Ketiga, pihak matahari departement store Kota Ambon perlu menentukan segmentasi pasar yang jelas untuk konsumen yang dilayani. Hal tersebut dianggap perlu karena konsumen matahari departement store Kota Ambon kebanyakan yang berusia muda dan kebanyakan berbelanja bersama teman. Segmen pasar departement store Kota Ambon dapat didasarkan pada demografi konsumen sehingga kejelasan segmen akan membantu pihak departement store Kota Ambon dalam menentukan target pasar yang ditentukan. Keempat, Pihak matahari departement store Kota Ambon perlu meningkatkan kemampuan karyawan dalam hal melayani konsumen, hal ini desebabkan berdasarkan hasil studi menunjukan bahwa konsumen cenderung melakukan pembelian impulsif dikarenakan respons yang cepat dari karyawan dalam hal menerangkan spesifikasi produk dan membantu mereka dalam mencari produk yang diinginkan. Kelima, pihak matahari departement store Kota Ambon perlu melakukan pembenahan exterior dan interior agar departement store sebagai tempat belanja memberikan pengalaman belanja yang menyenangkan dan ekslusif. Pembenahan exterior meliputi warna bangunan. Pembenahan interior meliputi pengaturan musik yang diperdengarkan didalam departement store Kota Ambon.

\section{DAFTAR PUSTAKA}

Assael, Henry. 1987. Consumer Behavior and Marketing Action. Third Edition. Boston: PWS-KENT Publishing Company. 
Bruner, C. Gordon. 1990. Music, Mood, and Marketing. Journal of Marketing, Vol.54, No.4 pp.94-104

Bayley, Geoff and Clive Nancarrow. 1998. Impulse Purchasing: A Qualitaive Exploration of the Phenomenon. An International Journal, Vol 2, pp.99-114 Baker, J., Grewal, D. and Parasuraman. 1994. The Influence of Store Environment on Quality Inferences and Store Image. Journal of the Academy of Marketing Science, 22 (4): 328-339.

Belk, Russel W. 1975. Situational Variable and Consumer Behavior. Journal of Consumer Research, Vol 2, December, pp157-164.

Bellenger, Dan H. Robertson, and Elizabeth C. Hirschman. 1978. Impulse Buying Varies by Product. Journal of Advertising Research. Vol 18. No.6, December, pg 15-18.

Boyd; Jr. Harper W.; Jr. Orville C. Walker; Jean-Claude Larreche. 2000. Manajemen Pemasaran: Suatu Pendekatan Strategis Dengan Orientasi Global. Jilid 2. Edisi Kedua. Jakarta: Erlangga.

Chang, Chih-Hon and Chia-Yu Tu. 2005. Exploring Store Image, Customer Satisfaction and Customer Loyalty Relationship: Evidence from Taiwanese Hypermarket Industry. The Journal of American Academy of Business, Cambridge Vol.7. Num.2. September.

Coley Amanda, and Burgess Brigitte. 2003. Gender Differences in Cognitive and Affective Impulse Buying. Journal of Fashion Marketing and Management Vol.7 No.3, 2003 pp.282-295

Cobb, Cathy J. and Wayne D. Hoyer. 1986. Planned Versus Impulse Purchase Behavior. Journal of Retailing. Vol 62. No 4.

Chang, H.,Eckman, M.,and Yan, R. 2009. Impulse Buying Behavior of Apparel: Aplication of the S-O-R Model and the Moderating Effect of Hedonic Motivation. ITAA Proceedings

Dholakia, U. M. 2000. Temptation and Resistance: an Integrated Model of Consumption Impulse Formation and Enactment. Psychology and Marketing. Vol 17 No. 11, pp955-982. 
Donovan, R. J. Rossiter, J. R. Marcoolyn, G. and Nesdale, A. 1994. Store Atmosphere and Purchasing Behavior. Journal of Retailing, 70(s): 283-294.

Engel, James F., Roger D. Blackwel., and Paul W. Miniard. 1994. Perilaku Konsumen. Edisi Keenam. Jakarta: Binarupa Aksara.

Ferdinand, Augusty. 2006. Metode Penelitian Manajemen: Penelitian Untuk Penulisan Skripsi, Tesis dan Disertasi Ilmu Manajemen. Semarang: Badan Penerbit Universitas Diponegoro.

Hatane, S. 2006. Bentuk Format Media Iklan Sebagai Stimulus Respon Emosi dan Kecenderungan Perilaku Pembelian Impulsif. Disertasi. Progam Pascasarjana Fakultas Ekonomi Universitas Brawijaya Malang.

Hausman, A. 2000. A Multi-method Investigation of Consumer Motivations in Impulse Buying Behavior. Journal of Consumer Marketing, Vol. 17 No. 5, pp. 403-417.

Kotler, Philip . 1973. Atmospherics as a Marketing Tool. Journal Vol. 49 Number 4 Winter.

Kotler, P. 1997. Manajemen Pemasaran: Analisis, Perencanaan, Implementasi, dan Pengendalian. Edisi Bahasa Indonesia. Jakarta: LPFE-UI.

Malhotra, N. K. 2005. Riset Pemasaran, Pendekatan Terapan. Edisi Keempat. Jakarta: Penerbit Indeks.

Ma'ruf, Hendri . 2005. Pemasaran Ritel. Jakarta: Penerbit PT. Gramedia Pustaka Utama.

Mattila, S. Anna and Fochen Wirtz. 2006. The Role Store Environmental Stimulation and Factors on Impulse Purchasing. Journal of Service Marketing: 562-567.

Mowen, J. C. and Michael Minor. 2001. Consumer Behavior. Fifth Edition, Harcourt, Inc.

Narwoko, J. Dwi dan Suyanto, Bagong. 2006. Sosiologi: Teks Pengantar dan Terapan. Jakarta: Kencana Prenada Media Group.

Nicholas, J. A. F., Sydney Roslow, Sandipa Dublish, and Lucette B. Comer. 1996a. Relationship Between Situational Variables and Purchasing in India and the USA. International Marketing Review. Vol 13 No 6. Pp 6-21. 
Nicholas, J. A. F., Sydney Roslow, Sandipa Dublish, and Lucette B. Comer. 1996b. Time and Companionship: Key Factors in Hispanic Shopping Behavior. International Marketing Review. Vol 14 No 3. Pp 194-205.

Peter, J. Paul and Jerry C. Olson. (2002), Consumer Behaviour and Marketing Strategy. Homewood. Illinois: Richard D.Irwin Incorporation.

Park, E.J.,Kim,Eun Yong., and Forney,J.C. (2005), A Structural Model of Fashion Oriented Impulse Buying Behavior. Journal of Fashion Marketing and Manajement Vol.10 No.4 pp. 433-446.

Riduwan, dan Kuncoro. (2007), Analisis Jalur (Path Analysis): Cara Menggunakan dan Memakai. Cetakan Kedua, Jakarta: Penerbit Alfabeta.

Rohman, Fatchur. (2009), “Peran Nilai Hedonik Konsumsi dan Reaksi Impulsif Sebagai Mediasi Pengaruh Faktor Situasional Terhadap Keputusan Pembelian Impulsif di Butik Kota Malang". Disertasi. Progam Pascasarjana Fakultas Ekonomi Universitas Brawijaya Malang. 